\title{
ISOLATED FRACTURE OF THE TROCHLEA: REPORT OF TWO CASES WITH REVIEW OF THE LITERATURE ON THE MECHANISM OF INJURY
}

Kunal Dhurve ${ }^{1}$, Vishal S Patil ${ }^{2}$, A S Chandanwale ${ }^{3}$, R G Puranik ${ }^{4}$.

1. Consulting Orthopedic Surgeon, Department of Orthopedics, Advanced Orthopedic And Joint replacement Centre Thane,

2. Assistant Professor, department of Orthopedics, BJGMC, Pune.

3. Professor, Department of Orthopedics, BJGMC, Pune.

4. Assistant Professor, department of Orthopedics, BJGMC, Pune.

\section{CORRESPONDING AUTHOR}

\section{Dr Vishal S Patil,}

House No.93, survey no 16,

lane no 3, Madhuban Society,

Sangvi, Pune 411027.

Email- vishal4sp@rediffmail.com

\section{HOW TO CITE THIS ARTICLE:}

Kunal Dhurve, Vishal S Patil, A S Chandanwale, R G Puranik. "Isolated fracture of the trochlea: Report of Two Cases with Review of the Literature on the Mechanism of Injury". Journal of Evolution of Medical and Dental Sciences 2013; Vol2, Issue 26, July 1; Page: 4805-4812.

INTRODUCTION: Also called as Laugier's fracture, isolated fracture of the humeral trochlea is a rare clinical entity1. Trochlear fracture is usually associated with dislocation of the elbow ${ }^{2}$.The exact mechanism causing this peculiar type of fracture is not known precisely. We present two cases of isolated displaced fracture of the trochlea treated by open reduction and internal fixation. The literature regarding the mechanism of injury is reviewed.

\section{CASE HISTORY: -}

CASE 1: A 16 year old school going boy presented to the emergency department with pain and swelling in his elbow following fall from a bicycle. He fell on his outstretched hand with forearm pronated and the elbow partially flexed. On examination, the left elbow was swollen with tenderness over the antero-medial aspect. The elbow range was restricted and painful. Radiological examination revealed a crescentic shadow on the anterior aspect of the distal humerus on lateral view (Fig 1 Preoperative radiograph of case 1 showing cresentic shadow of trochlear fragment on lateral view). The capitellar shadow was normal on antero-posterior view. Further investigation with CT scan revealed a coronal shear fracture of trochlea with antero-superior displacement of the fractured fragment (Fig 2 CT scan of case 1 depicting antero-superior displacement of fracture fragment).

Patient was operated on seventh day post-injury. Examination at the time of surgery revealed varus instability both in 90 degree flexion and extension. Since the capitellum was intact and displacement of fracture fragment was anterior, antero-medial approach through the interval between flexor pronator muscles medially and the brachialis muscle laterally was utilized. After capsulotomy the trochlear fragment was found to be completely loose and had a metaphyseal spike over the medial aspect. The fragment was reduced and fixed with a Herbert screw placed in the 


\section{ORIGINAL ARTICLE}

antero-posterior direction to achieve an inter fragmentary compression. For additional stability the metaphyseal spike was fixed with a $4 \mathrm{~mm}$ cancellous screw. The reduction was confirmed by direct visualization and fluoroscopic examination. The elbow was immobilized in $90^{\circ}$ flexion with the help of a splint for five days after which active assisted range of motion exercises were started. Passive range of motion exercises were started six weeks after the surgery. At three months of follow up the patient had regained full pronation and supination. The flexion and extension movements were in the range of $20^{\circ}$ to $100^{\circ}$. Radiographs showed maintained reduction with evidence of union (Fig 3 Post-operative radiographs of case 1 showing united fracture). At two years follow up, range of motion improved to $10^{0}-130^{0}$. There was no instability.

CASE 2: A 30 year old female presented to the emergency department following a fall from motorbike while riding pillion with her husband. She fell on her outstretched arm with forearm in supination and elbow extended. On examination there was swelling at the elbow predominantly over the medial aspect with ecchymosis extending on to the medial and anterior aspect of the forearm. Movements of the elbow were painful and severely restricted. Radiological examination revealed comminuted fracture of medial lip of trochlea (Fig 4 Pre-operative radiographs of case 2 showing fracture of medial lip of trochlea). Patient was operated on fourth day post-injury. Examination under anaesthesia revealed varus instability in extension. Medial approach was used to expose the fracture site. Common flexor muscle origin was partly erased from the medial epicondyle. Anatomical reduction was achieved and the fracture was fixed with a Herbert screw placed in medio-lateral direction. Stability and range of movements were checked after the fixation. The erased flexor origin was reattached to the medial epicondyle using non-absorbable sutures. The elbow was splinted in above-elbow slab for five days and active assisted range of motion exercises were started thereafter. Passive range of motion was started at six weeks. At one year follow-up, radiograph revealed fracture union (Fig 5 Post-operative radiograph of case 2 at one year showing fracture union) and patient had $10^{0}-140^{\circ}$ degrees range of motion (Fig 6 Elbow range of motion of case 2 at one year follow-up). There was no instability.

DISCUSSION: Isolated fracture of the humeral trochlea is a rare entity as compared to its counterpart, the capitellar fracture. The reported incidence of isolated capitellar fractures is $10 \%$ of all distal humeral fracture while the incidence of trochlear fractures is even less ${ }^{3}$.Till date only eight cases of isolated trochlear fractures have been reported 4-10.

The proposed reasons as for its rare occurrence in isolation are:

Being confined within the depth of the elbow joint, the trochlea usually remains intact in direct elbow injuries 9.

Trochlea has no muscular or ligamentous attachments; therefore, it is not fractured by indirect forces ${ }^{8}$.

The ulno-humeral joint is not commonly subjected to shear forces that occur at the radiocapitellar joint ${ }^{8}$.

Forces required for trochlear fractures can also lead to elbow dislocation. (Hence it frequently occurs in association with elbow dislocation) 6.

Peculiar structure of trochlea protects it from injury 8. 


\section{ORIGINAL ARTICLE}

Furthermore, biomechanically, humero-ulnar joint shows a concave incongruity. According to Eckstein, with concave incongruity the position of contact area shifts from the joint margin towards the center as the load increases and the peak stresses are considerably lower ${ }^{11}$.This can be one of the contributing factors for the rarity of trochlear fracture.

The mechanism of injury for capitellar fracture is well described in literature; however, ambiguity prevails regarding the mechanism of injury responsible for the trochlear fractures. (Table1).

TABLE1: Mechanism of injury for the cases described in literature.

\begin{tabular}{|c|c|c|}
\hline Author & Mechanism of injury & Fracture pattern \\
\hline $\begin{array}{l}\text { Worrel } \\
(1971)\end{array}$ & Axial load in extension & Coronal shear \\
\hline $\begin{array}{l}\text { Kaushal } \\
\text { (2005) }\end{array}$ & Axial load in extension & Coronal shear \\
\hline $\begin{array}{l}\text { Nakatani } \\
(2005)\end{array}$ & $\begin{array}{l}\text { Not certain; proposed mechanism of action is axial } \\
\text { load in extension }\end{array}$ & $\begin{array}{l}\text { Facture of the medial lip of } \\
\text { trochlea }\end{array}$ \\
\hline Foulk (1995) & $\begin{array}{l}\text { Not certain; proposed mechanism is axial load in } \\
\text { flexion }\end{array}$ & Coronal shear \\
\hline Singh (2010) & Axial load in flexion & Coronal shear \\
\hline $\begin{array}{l}\text { Kwan (2007) } \\
\text { Case I }\end{array}$ & $\begin{array}{l}\text { Axial load in flexion with forearm in pronation } \\
\text { Direct trauma to elbow in flexion }\end{array}$ & Coronal shear \\
\hline Case II & & $\begin{array}{l}\text { Facture of medial lip of } \\
\text { trochlea }\end{array}$ \\
\hline
\end{tabular}

Among the reported cases in literature, we found three different mechanisms that could be responsible for the occurrence of this fracture: Axial load in flexion, axial load in extension and direct impact on the elbow in flexion. Also, two distinct fracture patterns were identified: Type I - Coronal shear fracture; Type II- Fracture of medial lip of trochlea.

Coronal shear fracture (type I) occurs because of impact of the coronoid process on the anterior part of trochlea with resultant antero-superior displacement of the fracture fragment. Kwan ${ }^{9}$ stated that, due to the unique articular relationship of the elbow, the resultant force acting on distal humerus is the function of the degree of elbow flexion and the direction of applied force. Thus a combination of various factors can modify the resultant force acting on distal humerus. Due to this, more force can be transmitted to the trochlea through the coronoid process in certain positions of the elbow and forearm, resulting in its isolated fracture. Jupiter ${ }^{12}$ described a case of multiplanar fracture of distal humerus having coronal shear fractures of the trochlea as one of the component. He stated that in the flexed position, the elbow acts as a fulcrum, and force transmitted through it in this position can result in trochlear fracture. Biomechanical studies also suggest that the direction of forces acting over the ulno-trochlear articulation vary with the degree of flexion of the elbow and forearm position ${ }^{13,} 14$.Eckstein showed that, at $30^{\circ}$ flexion ventral contact area in elbow is significantly greater than the dorsal contact area ${ }^{15}$.Hence it can be postulated that axial loading in flexed position would transmit the forces along the ventral surface of trochlea through the coronoid. 


\section{ORIGINAL ARTICLE}

Axial loading in extension as a mechanism of isolated coronal trochlear fractures is also reported by few authors ${ }^{4,7}$. Oppenheim ${ }^{16}$ described a peculiar case of concomitant fracture of the trochlea and capitellum. He suggested that both these fractures occurred due to shear force transmission from the radial head and coronoid to the capitellum and the trochlea respectively in extended position. Case 1 in our series is coronal shear fracture (Type I) and was caused by axial loading in flexion. Axial loading in extended position of elbow can produce varus stress in elbow wherein the medial aspect of coronoid abuts against the medial lip of trochlea. This leads to a split fracture of the medial lip of trochlea (Type II). This mechanism is analogous to the split fracture of the tibial condyle. Direct trauma to the elbow as a mechanism of injury for fracture of the medial lip of trochlea is also reported ${ }^{9}$. Case 2 in our series is a split depression fracture of medial lip of trochlea and was caused by axial loading in extension.

For undisplaced fracture, non-operative treatment in the form of posterior splint immobilisation is recommended 17, 18. For displaced fractures, accurate anatomical reduction and stable fixation is the ideal treatment to achieve satisfactory outcome. Sabo ${ }^{19}$ performed a biomechanical study on eight cadavers to study the effect of coronal shear fractures of the distal humerus on elbow kinematics and stability. He concluded that excision of the trochlea resulted in multiplanar instability of the ulno-humeral and radio-capitellar joints. Hence he advocated against excision of all or a part of the trochlea. All the cases reported in literature were treated operatively and yielded good results.

As the osteochondral fragment of trochlea has no muscular or ligamentous attachments, osteonecrosis is expected in these cases by convention. However, there is no evidence of osteonecrosis in the reported cases in literature.

CONCLUSION: Isolated fracture of the trochlea is a rare entity. Mechanism of injury is still unclear; interplay of various factors can result in force transmission predominantly to the trochlea leading to its fracture in isolation. Two different fracture patterns can be recognized; the coronal shear type and the medial lip fracture. Maintenance of articular congruity, stable fixation and early range of motion yield good results. Further studies detailing the mechanism of injury responsible for the fracture of the trochlear are required.

\section{REFERENCES:}

1. Stimson LA (1890) A treatise on fractures. Henry C Lea and Son Co., Philadelphia

2. Grant IR, Miller JH (1975) Osteochondral fracture of the trochlea associated with fracturedislocation of the elbow. Injury 6:257-260

3. Ring D (2006) Fractures and dislocations of the elbow. In: Bucholz RW, Heckman JD, CourtBrown CM (ed). Rockwood and Green's fractures in adults, 6th edn. Lippincott, Philadelphia, pp991-1049

4. Worrell RV (1971) Isolated, displaced fracture of the trochlea. NY State J Med 71:2314-5

5. Oberstein A, Kreitner KF, Lowe A, Michiels I (1994) Isolated fracture of trochlea humeri following direct elbow trauma. Aktuelle Radiol 4(5):271-3 (Article in German)

6. Foulk DA, Robertson PA, Timmerman LA (1995) Fracture of trochlea. J Orthop Trauma 9(6):530-2 


\section{ORIGINAL ARTICLE}

7. Kaushal R, Bhanot A, Gupta PN, Raj Bahadur (2005) Isolated shear fracture of humeral trochlea Inj Extra 36(6):210-211

8. Nakatani T, Sawamura S, Imaizumi Y et al (2005). Isolated fracture of the trochlea: a case report. J Shoulder Elbow Surg 14(3):340-343

9. Kwan MK, Khoo EH, Chua YP, Mansor A (2007) Isolated displaced fracture of humeral trochlea: a report of two rare cases. Injury Extra 38(12):461-465

10. Singh AP, Dhammi IK, Jain AK, Jain S (2010) Neglected isolated fracture of the trochlea humeri. Chin J Traumatol 13(4):247-249

11. Eckstein F, Merz B, Muller-Gerbl M, Holzknecht N, Pleier M, Putz R (1995) Morphomechanics of the Humero-Ulnar Joint: II. Concave incongruity determines the Distribution of Load and Subchondral Mineralization. Anat Rec 243:327-335

12. Jupiter JB, Barnes KA, Goodman LJ, Saldana AE (1993) Multi plane fracture of distal humerus. J Orthop Trauma 7(3):216-220

13. Chou PH, Lin CJ, Chou YN, Lou SZ, Su FC, Huang GF (2002) Elbow Load with Various Forearm Positions During One-Handed Push up Exercise. Int J Sports Med 23: 457-462

14. Chou PH, Lou SZ, Chen HC, Chiu CF, Chou YL (2009) Effect of various forearm axially rotated postures on elbow load and elbow flexion angle in one-armed arrest of a forward fall. Clin Biomech 24:632-636

15. Eckstein F, Lohe F, Hillebrand S, Bergmann M, Schulte E, Milz S, Putz R (1995) Morphomechanics of the Hurnero-Ulnar Joint: I. Joint Space Width and Contact Areas as a Function of Load and Flexion Angle. Anat Rec 243:318-326

16. Oppenheim W, Davlin LB, Leipzig JM, Johnson EE (1989) Concomitant fractures of the capitellum and trochlea. J Orthop Trauma 3:260-2.

17. Smith FM (1972) Surgery of the elbow. 2nd edn. Saunders, Philadelphia

18. Egol KA, Koval KJ, Zuckerman JD (2010) Handbook of Fractures $4^{\text {th }}$ edn. Lippincott Williams \& Wilkins, Philadelphia

19. Sabo MT, Fay K, McDonald CP, Ferreira LM, Johnson JA, King GJ (2010) Effect of coronal shear fractures of the distal humerus on elbow kinematics and stability. J Shoulder Elbow Surg 19(5):670-80 


\section{ORIGINAL ARTICLE}

FIGURE 1: Preoperative radiograph of case 1 showing crescentic shadow of trochlear fragment on lateral view

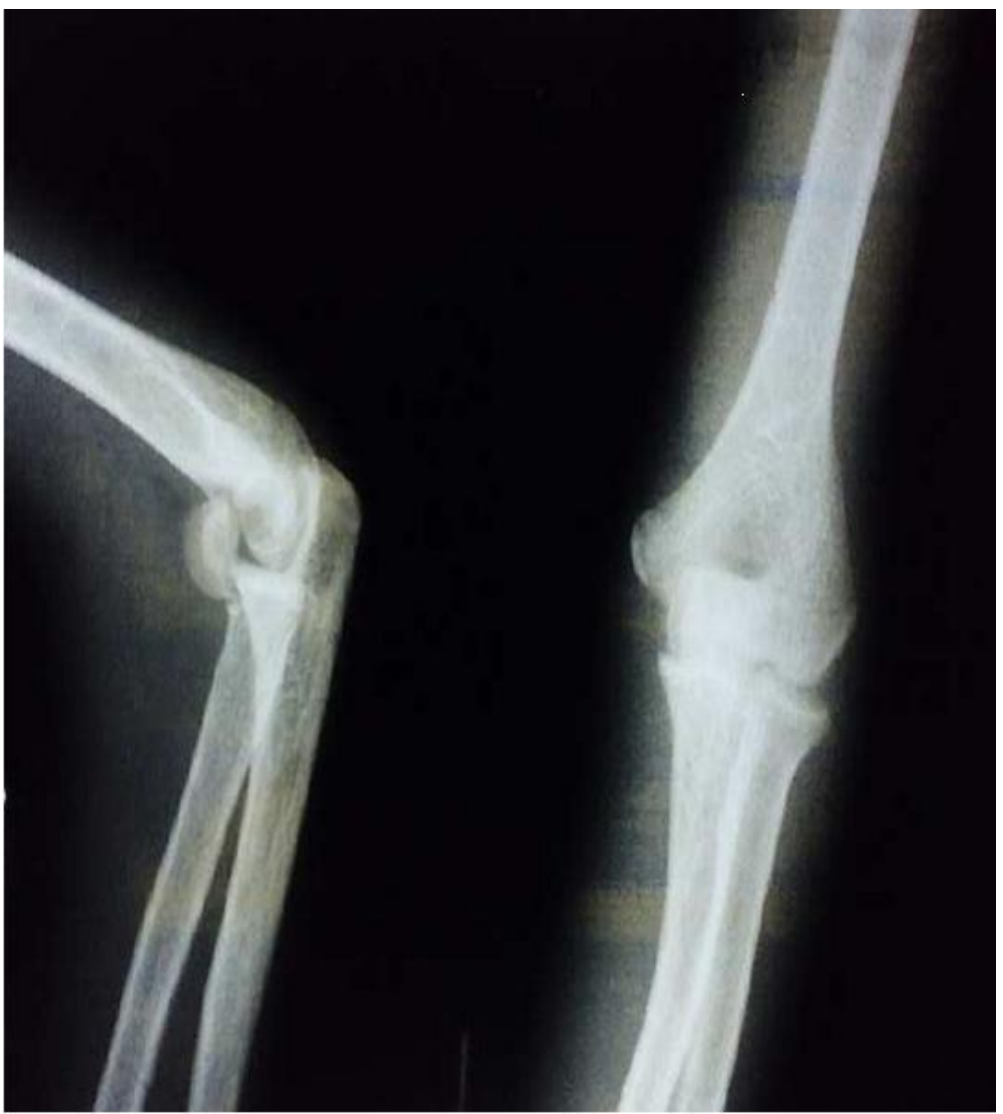

FIGURE 2: CT scan of case 1 depicting antero-superior displacement of fracture fragment

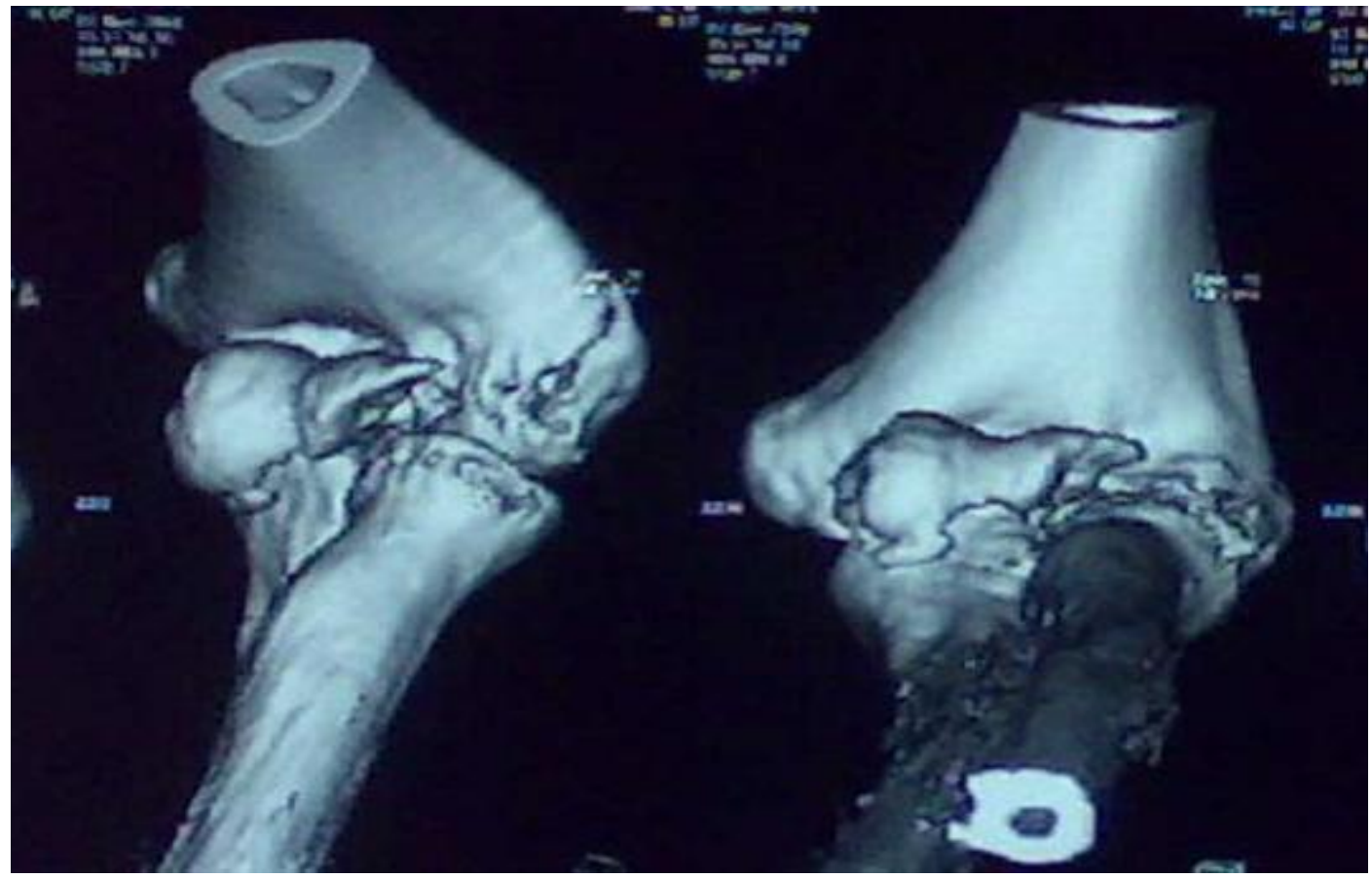




\section{ORIGINAL ARTICLE}

FIGURE 3: Post-operative radiographs of case 1 showing united fracture

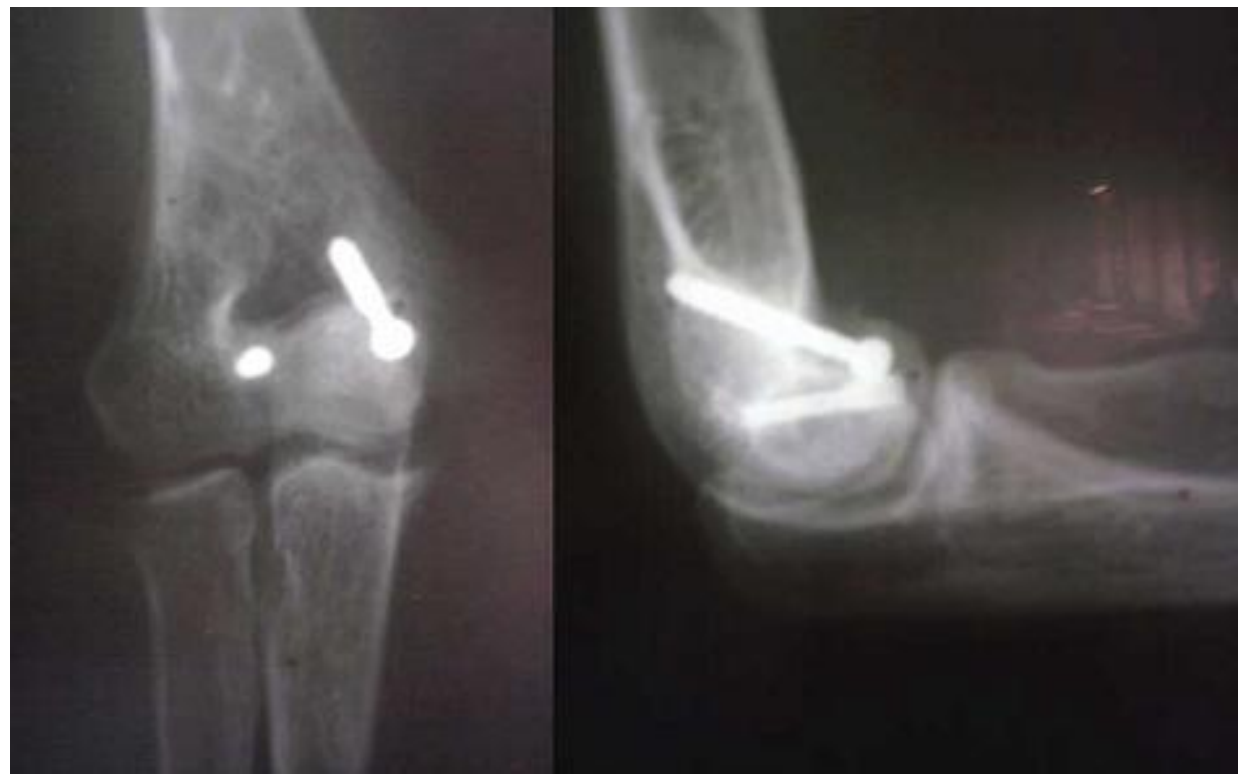

FIGURE 4: Pre-operative radiographs of case 2 showing fracture of medial lip of trochlea

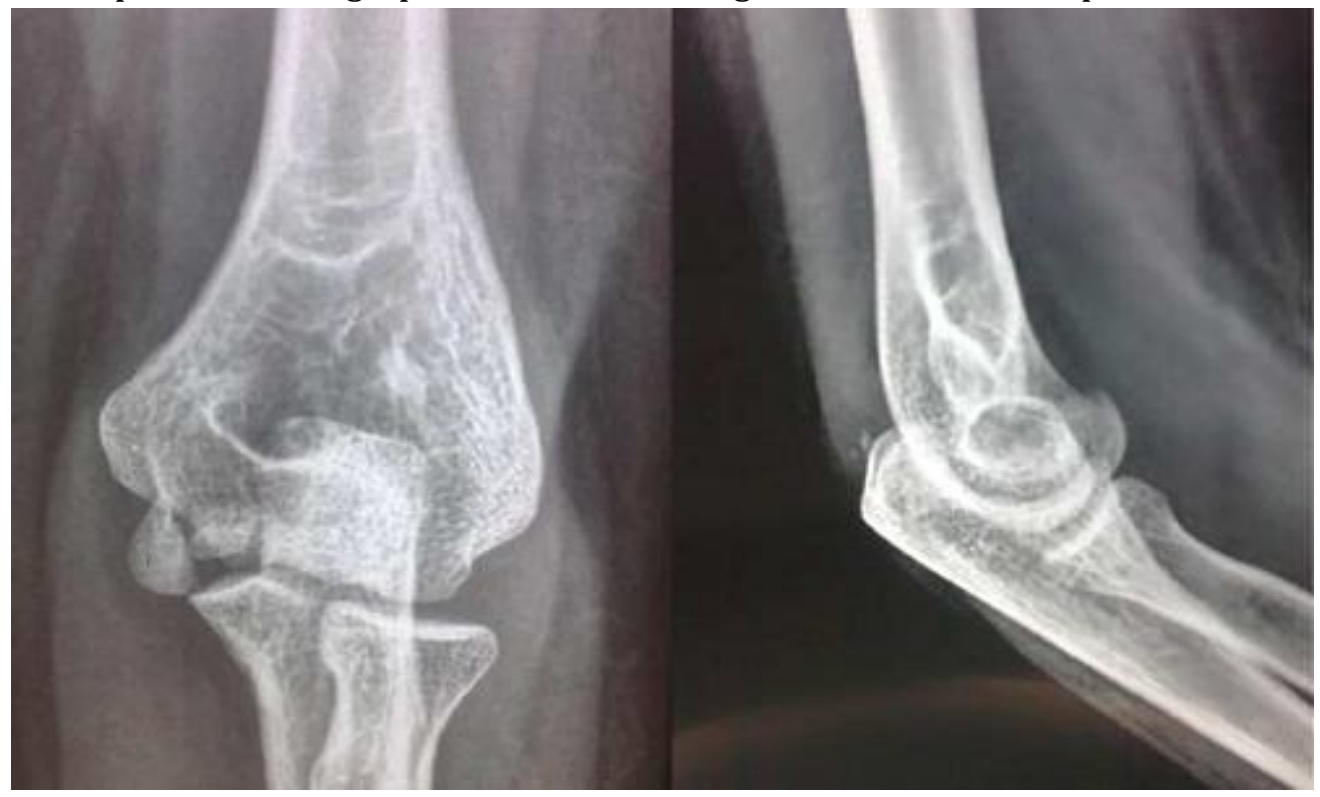




\section{ORIGINAL ARTICLE}

FIGURE 5: Post-operative radiograph of case 2 at one year showing fracture union

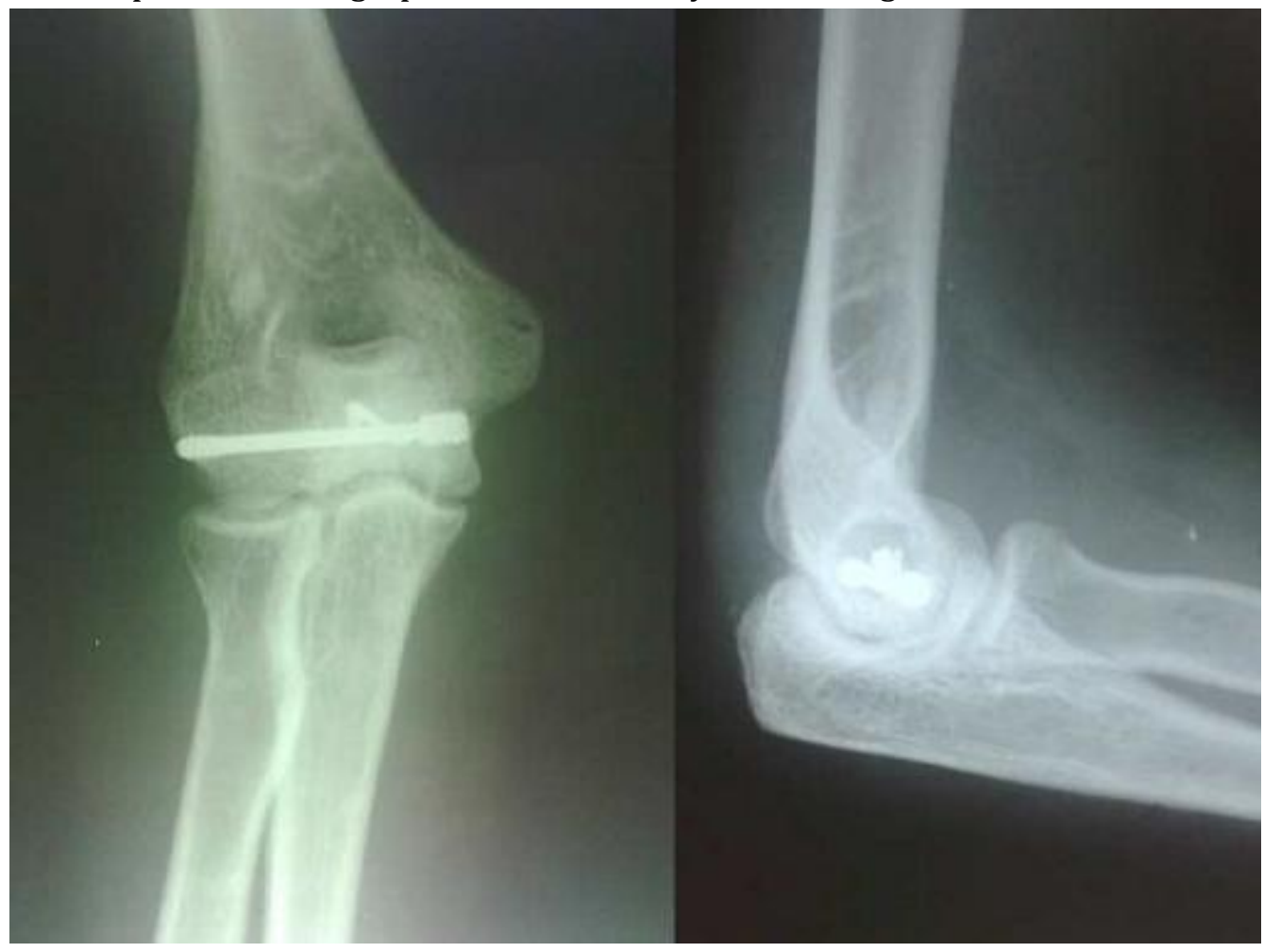

FIGURE 6: Elbow range of motion of case 2 at one year follow-up
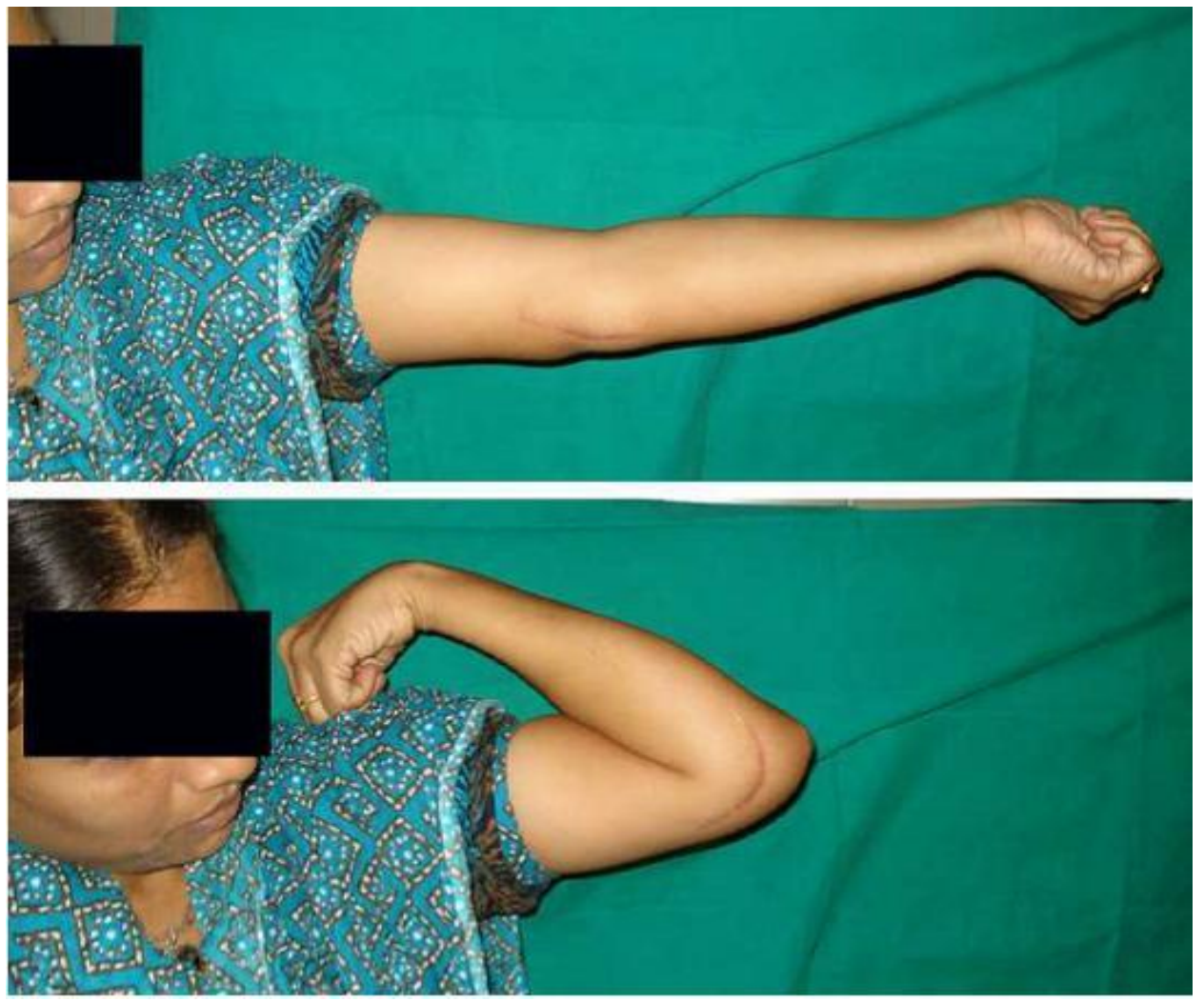

Journal of Evolution of Medical and Dental Sciences/ Volume 2/ Issue 26/ July 1, 2013 